\title{
The Comportmental Learning Disabilities of Early Frontal Lobe Damage
}

\section{Citation}

Price, Bruce H., Kirk R. Daffner, Robert M. Stowe, and M. Marsel Mesulam. 1990. "The Comportmental Learning Disabilities of Early Frontal Lobe Damage." Brain 113, no. 5: 13831393.

\section{Published Version}

10.1093/brain/113.5.1383

\section{Permanent link}

http://nrs.harvard.edu/urn-3:HUL.InstRepos:12605379

\section{Terms of Use}

This article was downloaded from Harvard University's DASH repository, and is made available under the terms and conditions applicable to Other Posted Material, as set forth at http:// nrs.harvard.edu/urn-3:HUL.InstRepos:dash.current.terms-of-use\#LAA

\section{Share Your Story}

The Harvard community has made this article openly available.

Please share how this access benefits you. Submit a story.

\section{Accessibility}




\title{
THE COMPORTMENTAL LEARNING DISABILITIES OF EARLY FRONTAL LOBE DAMAGE
}

\author{
by BRUCE H. PRICE, KIRK R. DAFFNER, ROBERT M. STOWE and
}

M. MARSEL MESULAM

(From the Bullard and Denny-Brown Laboratories, the Division of Behavioral Neurology and Neuroscience of the Harvard Neurology Department and the Charles A. Dana Research Institute of the Beth Israel Hospital, Boston, USA)

\section{SUMMARY}

Two adult patients are described who suffered bilateral prefrontal damage early in life and who subsequently came to psychiatric attention because of severely aberrant behaviour. A battery of developmental psychology paradigms (not previously used to assess neurologically impaired individuals) showed that social and moral development of these 2 patients was arrested at an immature stage. In comparison with other types of brain damage which disrupt cognitive development, frontal damage acquired early in life appears to provide the neurological substrate for a special type of learning disability in the realms of insight, foresight, social judgement, empathy, and complex reasoning.

\section{INTRODUCTION}

Most of the available literature on the behavioural affiliations of the human frontal lobe is based on the clinical examination of patients with lesions acquired during adulthood (Ackerly, 1935; Brickner, 1936; Hebb, 1945; Benton, 1968; Milner, 1982; Eslinger and Damasio, 1985; Lhermitte, 1986; Lhermitte et al., 1986). Comparatively little information is available about the behavioural outcome of lesions acquired early in life or in the course of embryogenesis. Such information could help to identify the behaviours that depend on the frontal lobes for their acquisition and development.

This report describes 2 individuals who sustained severe frontal lobe damage early in life and subsequently displayed major behavioural abnormalities as adults. These observations suggest that the frontal lobe plays an essential role in the maturation of complex comportmental skills, formal operational thought, social conduct and moral judgement.

\section{CASE REPORTS}

Case 1

G.K. is a $31-\mathrm{yr}$-old right-handed man who has been given multiple diagnoses, including antisocial or borderline personality, atypical psychosis, and paranoid schizophrenia. Because of increased head circumference over the first 7 days of life, bilateral ventricular punctures were performed which yielded $10 \mathrm{ml}$ of subdural haematoma fluid. Air was injected after aspiration and an irregular collection in the left frontal lobe was demonstrated. He was discharged 7 wks after birth when his head circumference had stabilized and he was thriving.

Correspondence to: Dr Bruce H. Price, Neurological Unit, Beth Israel Hospital, 330 Brookline Avenue, Boston, MA 02215, USA.

Dr Stowe is now at the Veterans Administration Medical Center, Pittsburgh, Pennsylvania, USA. 
Detailed history from multiple sources revealed that he was always considered immature but that serious behavioural difficulties were first identified by the age of $8 \mathrm{yrs}$. He did not respond to parental discipline, always sought gratification of his immediate needs, never developed adequate friendships, and blamed his difficulties on others. Though gregarious, he was irresponsible, tended to wander, and consistently fell under the influence of other deviant children. Under firm guidance and after two school transfers, he graduated from high school. He joined the Marine Corps but was dishonourably discharged 6 wks later. Over the next $10 \mathrm{yrs}$, he was hospitalized 27 times in psychiatric institutions and imprisoned 8 times on charges of assault, forgery (using his father's cheque book), grand larceny, drug involvement and lewd behaviour. Inappropriate behaviours were numerous. While walking by a gas station he saw an unattended taxi with keys in the ignition. He jumped in and drove off, ripping the hose from the gas pump, only to be captured several blocks away. When restricted for inappropriate behaviour by a ward attendant, he escaped from the locked psychiatric unit, scratched the attendant's car with broken glass, signed his own name, and re-entered the ward. When confronted, he denied his involvement. The only 2 people he claimed as friends were involved with him in abusing marijuana, alcohol, LSD, and phencyclidine. He was charged with arson of two public buildings. He is an active bisexual, often trades cigarettes for oral sex, and masturbates in public. He was a suspect in the rape of 2 female ward patients. Neither individual psychotherapy nor trials on multiple psychoactive agents were effective.

The patient has 5 younger brothers. One suffers from mild mental retardation of unknown aetiology. Four siblings are college graduates, 1 is a lawyer. His father successfully operates a landscape business. His mother was trained as a nurse and suffers from depression and alcoholism. There is no other significant family psychiatric history. The family environment was not particularly chaotic or stressful.

Neurological examination revealed an overly familiar, impulsive, but cooperative man. He showed little insight or empathy and felt victimized by others. Other than a minimal left central facial paresis, the examination was unremarkable, without grasp, suck or root reflexes. Formal neuropsychological testing revealed a WAIS-Revised verbal IQ of 102, Performance IQ of 90, and Full-Scale IQ of 96 (Wechsler, 1981). No primary memory, language or visuospatial difficultics were demonstrated. Deficits were confined to attentional, organizational, and mental flexibility skills. For example, severe deficits were seen on Part B of the Trail Making Test (Reitan, 1958), Stroop Interference (Stroop, 1935), Wisconsin Card Sorting (Berg, 1948), Luria hand-motor sequences (Luria, 1973), auditory go-no-go (Luria, 1973), and the visualverbal test (Feldman and Drasgow, 1959). Word list generation (Benton and de Hamsher, 1976), and traditional office tests of abstraction and proverb interpretation were normal (Table 1).

General medical examination, laboratory tests, and routine EEG were normal. Axial MRI images using $\mathrm{T} 1$ and $\mathrm{T} 2$-weighted sequences revealed bilateral lesions extending from cortex to the caudate nuclei, more on the left than the right. There was mild ex vacuo enlargement of the right lateral ventricle (fig. 1).

TABLE 1. NEUROPSYCHOLOGICAL PROFILE OF CASE I

Test

WAIS-R

Verbal IQ

Performance IQ

Full Scale IQ

Digit Span

Word Generation (E/A/S)

Stroop Interference

Trails B

Wechsler Memory Scale

Boston Naming Test

Hooper Visual Organization Test

Visual-Verbal Test
Score

$\begin{array}{ll}102 & \begin{array}{l}\text { Average } \\ \text { Average } \\ 90 \\ \text { Average }\end{array} \\ 96 & \\ 7 \text { forward/4 backward } & \text { Mild inattention } \\ 17 / 7 / 11 & 57 \text { th percentile } \\ 143 \mathrm{~s} / 6 \text { errors } & <1 \text { st percentile } \\ & <1 \text { st percentile } \\ 86^{*} & 18 \text { th percentile } \\ 54 / 60 & 31 \text { st percentile } \\ 14 / 15 & \text { Normal } \\ 0 / 5 & \text { Abnormal }\end{array}$

* Although the Wechsler Memory Scale suggests low average memory, no memory difficulties were apparent in his daily living activities. 

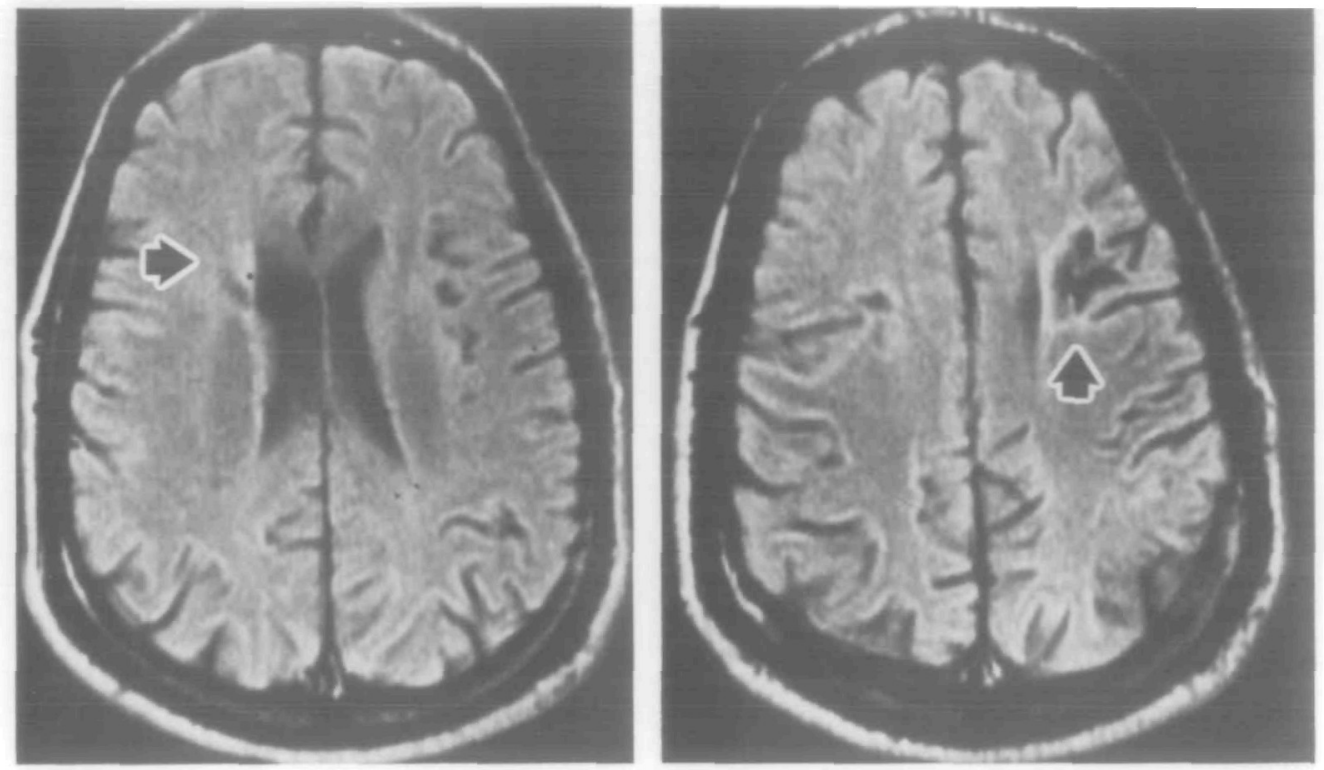

FIG. 1. Case 1. Axial MRI scan showing bilateral frontal lobe lesions. The left side of the head is on the right of the scan. Left involvement is greater than right. The lesions extend from cortex to the caudate nuclei. Mild ex vacuo enlargement of the right lateral ventricle can be seen.

\section{Case 2}

M.H. is a 26-yr-old ambidextrous woman who was referred by the Massachusetts Department of Social Service for inappropriate behaviour and negligent care of her $21 / 2$-month-old infant. She was developing appropriately until $4 \mathrm{yrs}$ of age, when she was struck by an automobile. She was unconscious for $48 \mathrm{~h}$ and suffered bilateral skull fractures and a right frontal haematoma.

Over the next year she began to exhibit temper outbursts when frustrated. She became verbally and physically assaultive in an abrupt, unpredictable, and short-lived manner. She hit her brother, threw her father over a table, and cut her sister with glass. Family members lived in constant terror and once called the police when she threatened them at knife point. She repeated the first and second grades and was given special tutorials in English, social studies, and reading. She graduated from high school at age $20 \mathrm{yrs}$. Since her early teens, she was known for her sexual promiscuity and bravado. She intermittently engaged in heavy alcohol and marijuana use. She had no sustained friendships.

After high school graduation, she held several temporary menial jobs where infrequent outbursts against coworkers or customers occurred. Although free of major depressive symptoms, she impulsively attempted suicide twice, once with an overdose of hypnotics, and another time by jumping out of a second floor window.

At age $17 \mathrm{yrs}$, she was raped while wandering through a local cemetery, but returned to the scene and was raped again by the same man. Her first pregnancy was terminated by an elective abortion, another ended in miscarriage, and her third accidental pregnancy yielded a daughter despite her parents' and boyfriend's pleas for an abortion. She under-dressed the baby in inclement weather, fed her erratically and left her unsupervised for lengthy periods of time. There were suspicions of physical assault. At 20 days of age, the patient's daughter was placed in foster care. This intervention infuriated the patient who saw nothing wrong with her child care. She attacked the social worker, and threatened to kill members of the social service agency. At her last follow-up visit in our unit, she was pregnant again but was uncertain who the father might be. Individual psychotherapy did not significantly alter her behaviour nor did a prolonged trial of anticonvulsant agents. 
The patient is the fourth of 6 children. None of her 5 siblings has similar behavioural problems. Her father is an optician and her mother is employed as a purchasing agent. Besides the father's occasional alcohol abuse, there is no history of psychiatric disease in the family.

Neurological examination revealed a somewhat diffident, but cooperative woman with limited insight. Other than skull deformities over the right orbit and temporal region, and a slightly increased left knee jerk, examination was normal.

WAIS-Revised testing estimated a Verbal IQ of 78, Performance IQ of 83, and Full Scale IQ of 78 (Wechsler, 1981). No deficits in memory or visuospatial abilities were noted. WRAT performance revealed deficiencies in reading (23rd percentile), spelling (32nd percentile) and mathematics (4th percentile) (Jastak and Jastak, 1965). Attention was slightly impaired with a digit span of 6 forwards and 6 backwards (Wechsler, 1981) and a Corsi block span of 5 forwards and 5 backwards (Milner, 1971). She identified 40 of 60 pictures on the Boston Naming Test plus 6 given additional naming cues (Kaplan et al., 1978). Moderate impairment was seen on tests of mental flexibility, sustained effort and abstract reasoning, such as the Trail Making Test, Part B (Reitan, 1958), Stroop interference (Stroop, 1935), word list generation (Benton and de Hamsher, 1976), visuoverbal (Feldman and Drasgow, 1959), and proverb interpretation tests (Table 2).

A 1980 routine awake EEG while the patient was on phenytoin was normal. An axial MRI scan revealed abnormal T1 and T2 signal intensities in both prefrontal regions with dilatation of frontal horns, greater on the left (fig. 2).

\section{TESTS OF PSYCHOLOGICAL DEVELOPMENT}

Logical thought, role-taking ability, social and moral reasoning undergo predictable stages of development which can be assessed quantitatively with the help of paradigms that have been validated extensively in many normative populations. We used these paradigms to test our 2 patients.

Piaget (1968) has shown that children go through stages of cognitive development which are characterized by successively more complex modes of information processing (i.e., thinking). According to Piaget's nomenclature, children undergo a sequence of cognitive development from sensorimotor $(0-2 \mathrm{yrs})$ to preoperational $(2-5 \mathrm{yrs})$, concrete operational $(6-10 \mathrm{yrs})$ and then formal operational thinking. Formal operational thinking (age $11 \mathrm{yrs}$ to adulthood) is based on hypothetical, deductive and propositional thought which allows the individual to predict the divergent outcomes that could result from a given set of actions. Research has indicated that the vast majorty of middle class Americans exhibit major components of formal operational thought by their early twenties (Kohlberg and Gilligan, 1971).

TABLE 2. NEUROPSYCHOLOGICAL PROFILE OF CASE 2

Test

WAIS

Verbal IQ

Performance IQ

Full Scale IQ

Digit Span

Word Generation (F/A/S)

Stroop Interference

Trails B

3 words $/ 3$ shapes* ( 10 and $30 \mathrm{~min}$ delay)

Boston Naming Test

Hooper Visual Organization Test

Visual-Verbal Test

\begin{tabular}{ll}
\multicolumn{2}{c}{ Score } \\
\hline 78 & Borderline \\
83 & Low average \\
78 & Borderline \\
& \\
6 forward/3 backward & Mild inattention \\
$13 / 9 / 5$ & 27 th percentile \\
$74 \mathrm{~s} / 7$ errors & 51 st percentile in time, \\
$99 \mathrm{~s} / 0$ errors & no errors is norm \\
$6 / 6$ & $<2$ 2nd percentile \\
$40 / 60$ & Normal \\
$(46 / 60$ with cues) & 18 th percentile \\
$26 / 30$ & \\
$4 / 5$ & Normal \\
& Normal
\end{tabular}

* This test is based on 3 simple designs and 3 words with low imagery value. Immediate incidental recall and recall after 10 and 30 min were intact (Weintraub and Mesulam, 1985). 

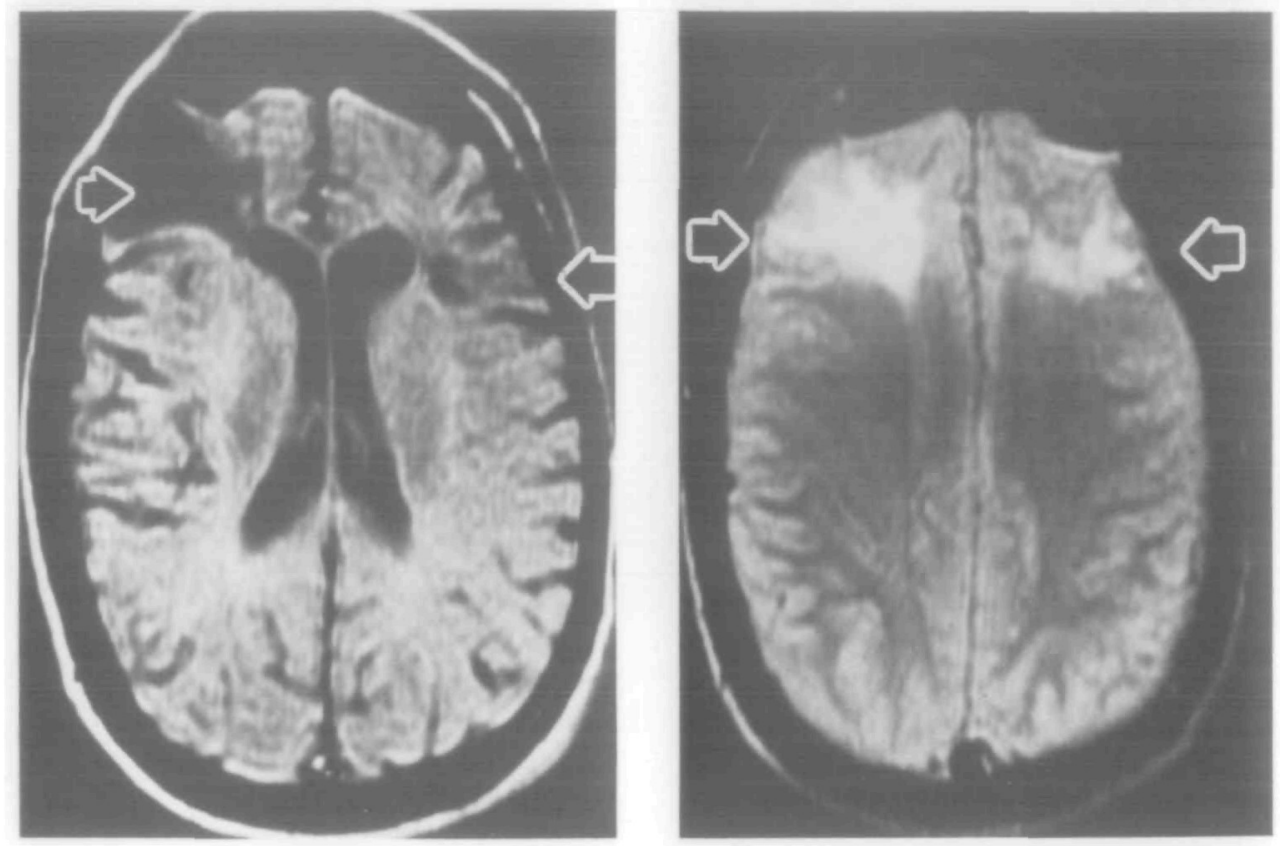

Fig. 2. Case 2. Axial MRI scans using $T 1$ and $T 2$ pulse sequences showing extensive damage confined to the frontal lobes. The left side of the head is on the right of the scan. Frontal horn dilatation is present, greater on the left.

Both our patients were able to perform a concrete operational task based on the recognition that the quantity of water remains unaltered when it is poured from a tall, narrow flask to a short but wider container. Neither patient, however, demonstrated formal operational thinking on the cognitive task described below.

Kuhn developed a problem based on presenting the subject with 4 plants, of which 2 look healthy and 2 unhealthy (Kuhn and Brannock, 1977). Each plant has been cared for in a different way with a combination of 1 of 2 kinds of plant food and 1 or 2 different amounts of water, with or without leaf lotion (fig. 3). The problem is constructed so that only one variable (plant food) determines the plant's health. In Kuhn's study of middle class students, only $15 \%$ of sixth graders failed to demonstrate any level of formal operational thought. Both our patients focused their attention on the problem but scored at the concrete operational level. They were unable to isolate the critical variable and failed to demonstrate formal operational thinking.

Selman (1971) has shown that a child is initially unable to differentiate his own perspective from that of another. Subsequent development allows the child to assume other perspectives and roles. The development of interpersonal empathy is presumably also dependent on the emergence of this capacity.

To investigate our patients' role-taking ability, a task developed by Flavell (1968) was given. It is performed by presenting the subject with a simple map and telling him that it is identical to one held by someone else lost in the countryside. The task requires the subject to take into account the location of the lost person, to suppress an egocentric perspective and, instead, to imagine how the lost person might interpret the message and respond to the instructions (fig. 4). Flavell demonstrated that while $75 \%$ of third graders found no more than 1 error, by the seventh grade $45 \%$ had found 2 errors and $40 \% 3$ or all of the 4 errors. Both our patients found the task engaging and carefully read the directions. Case 1 found only 2 errors. Case 2 was unable to recognize any errors saying 'The directions were fine'.

Kohlberg has described 6 stages of moral development based on a longitudinal study over the past $30 \mathrm{yrs}$ of 50 American boys (Kohlberg and Gilligan, 1971; Kohlberg, 1976) (Table 3). Studies suggest that by adolescence nearly $80 \%$ of middle class American boys have developed beyond preconventional moral reasoning (Kohlberg and Gilligan, 1971). 

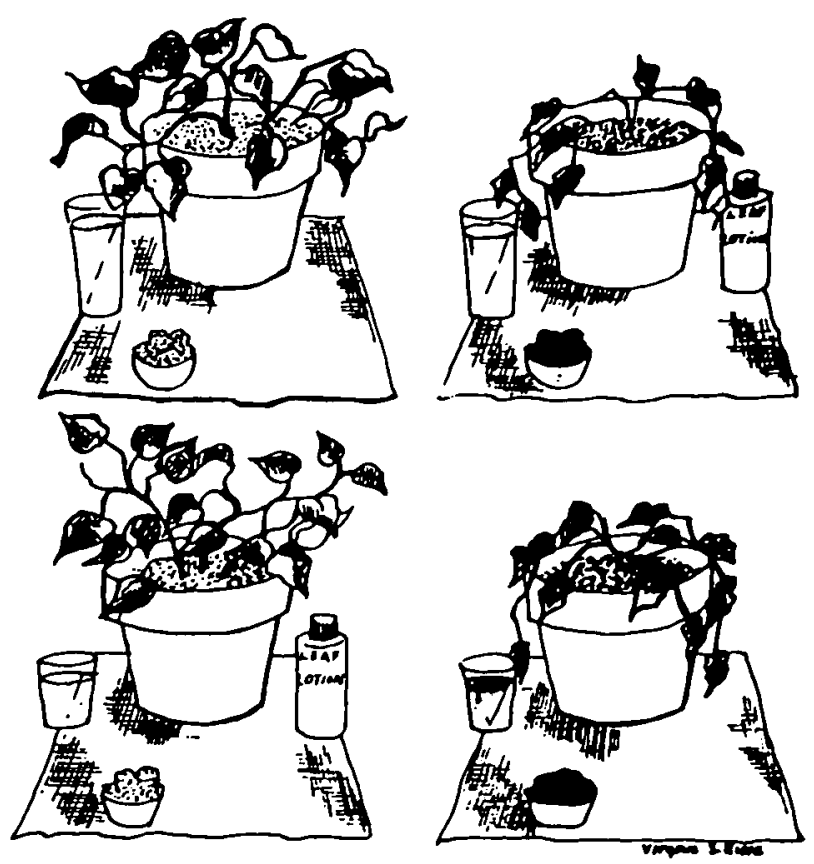

FIG. 3. Kuhn's plant problem. Two healthy and 2 dying plants are shown with different combinations of water volume, plant food (black and white), with or without leaf lotion. The subject's task is to isolate the one crucial variable (plant food) that determines the plant's health while excluding the inoperative variables (water and leaf lotion). Reproduced from Kuhn and Brannock (1977) with permission.

The 'Heinz dilemma', one of the paradigms used to assess moral development, asks the subject whether or not someone should steal a drug to save his dying wife. Case 1 responded at Kohlberg's early conventional level (stage 3), stating that Heinz should steal the drug 'because his wife is dying and human life is more important than money'. When asked why that should be, he responded 'because it is sacred. God put everyone on earth to do the best that he or she can and to help everyone out'. His reasoning about real life dilemmas revealed a more primitive preconventional orientation. After having impregnated a vulnerable and disturbed woman, his main concern was that 'Her father looked like Mean Joe Green. I wondered whether I would be killed now or later'. Case 2 responded to the Heinz dilemma at stage 1 of the preconventional level, and concentrated on her concerns about punishment. Heinz should not steal the drug because 'if you do it you're going to end up in jail. Then you'll fry in the electric chair'. At this primitive level, human interactions are viewed in physical, not psychological terms. People are seen as avenues or obstacles to gratification.

\section{DISCUSSION}

We have described 2 patients, aged 28 and 24 yrs at the time of our examination, who sustained brain injury at birth and 4 yrs of age. While we cannot be certain about the precise extent of the lesions, the neurodiagnostic, neurological and neuropsychological examinations indicated that the principal (if not exclusive) site of involvement was located bilaterally in the frontal lobes. Both patients displayed impulsive behaviour triggered by the immediate stimulus, performed with childish abandon and shallow foresight. Neither was able to learn from negative experience or punishment. Each patient remained 


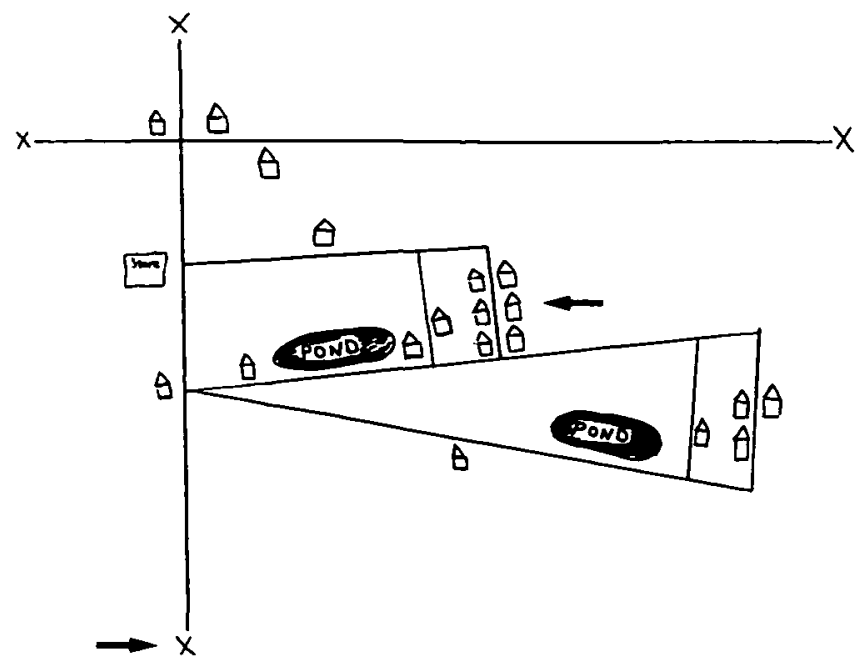

Fig. 4. Flavell's role-taking map test. The subject is instructed as follows. 'Now suppose there were a man in his car out in the country some place who got lost-he didn't know where he was or how to get to the house he wanted to go to. Now suppose he had this map (points) and I had exactly the same map here (points). Now he calls me up on the telephone and from what he says I can figure out where he is now. He is here (points to bottom $X$ on the map, and I can also tell him how to get to where he wants to go-there (points to second house on the right on the street which contains a cluster of six houses). I'm going to read out loud what I might tell him over the phone, and you may look along with me as I read. When I get through I want you to tell me what's wrong with the way I gave him the directions, why he'd have trouble getting there from what I say. Okay, now I'm going to talk to him on the phone.' The message is slowly read. 'If you look on your map you'll find an $X$. That's where you are right now. You go down the road until you see a house on your left. Turn right there and keep going until you pass a pond on your left. Then you make a left turn and the house you want is the second one on the street.' The subject is then asked to identify the ambiguities (total of 4) which might prevent the lost person from reaching the destination. The map is shown to the subject minus the designations of the lost person's present location $(\rightarrow)$ and destination $(-)$. Reproduced from Flavell (1986) with permission.

socially isolated without enduring friends, had little sense of remorse, empathy or fairness towards others but, instead, felt victimized. Both responded to firm parental and school guidance, but never acquired self-governance over their behaviour. Neither was raised in a particularly chaotic environment which could account for their life-long behavioural problems. Neither benefited from prolonged psychotherapy or medications. In comparison with the severe deficits of comportment, judgement and insight, neither patient displayed limiting deficits of language, memory or visuospatial skills in daily activities. The salient behavioural features in these patients are qualitatively similar to but appear quantitatively more intense than the behavioural deficits that emerge as a consequence of bilateral frontal lobe lesions acquired in adulthood.

Ackerly and Benton (1948) presented a 35-yr-old man who sustained bilateral frontal lobe damage around 3 yrs of age. The patient had 'normal' intelligence (Stanford-Binet IQ 92) but displayed behavioural abnormalities very similar to those in our patients. These included immaturity, inability to learn from experience, diminished insight, immersion in the present, lack of drive and curiosity, and irritability when crossed or restricted. When retested $15 \mathrm{yrs}$ later, his behaviour remained unchanged (Ackerly, 1964). Russell (1959) briefly mentioned a boy who at 5 months of age sustained frontal 
TABLE 3. STAGES OF MORAL DEVELOPMENT ACCORDING TO KOHLBERG (1976)*

Stage

Stage 1. Obedience and punishment orientation

Stage 2. Instrumental purpose and exchange

Stage 3. Interpersonal accord and conformity

Stage 4. Social accord and system maintenance

Stage 5. Social contract, utility, individual rights principles
What is considered to be right

To avoid breaking rules backed by punishment, obedience for its own sake, avoiding physical damage to persons and property

Following rules only when it is to someone's immediate personal interest; acting to meet one's own interests and letting others do the same; right is an equal exchange, a good deal

Living up to what is expected by people close to you or what people generally expect of people in your role; being good is important

Fulfilling the actual duties to which you have agreed; laws are always to be upheld except in extreme cases where they conflict with other fixed social duties; right is also contributing to society, the group, or institution

Being aware that people hold a variety of values and opinions, that most values and rules are relative to your group but should usually be upheld because they are the social contract; some nonrelative values and rights like life and liberty, however, must be upheld in any society regardless of the majority opinion

Stage 6. Universal ethical Following self-chosen ethical principles; particular laws or social agreements are usualy valid because they rest on such principles; when laws violate these principles, one acts in accordance with the principle; principles are universal principles of justice; the equality of human rights and respect for the dignity of human beings as individual persons; the reason for doing right is the belief, as a rational person, in the validity of universal moral principles and a sense of personal commitment to them

* Stages 1 and 2 characterize the preconventional level. Stages 3 and 4 represent the conventional level. Stages 5 and 6 occur at the postconventional level. Reproduced from Snarey (1985) with permission.

lobe damage from a bomb fragment. Severe behavioural problems were subsequently noted, including physical attacks on smaller children and the school cat, stealing, eating refuse, and deliberately emptying tea on his bed. His brothers and sisters were reportedly normal. A preliminary report describes a third case of early frontal injury leading to comportmental abnormalities during adulthood (Eslinger et al., 1989).

Recent evidence suggests that a specific learning disability such as dyslexia may be associated with developmental or early-acquired structural abnormalities located predominantly in the left hemisphere (Galaburda, 1988). Analogous involvement of the right hemisphere may lead to shyness, chronic emotional difficulties, poor paralinguistic abilities, and impaired visuospatial skills (Weintraub and Mesulam, 1983). Our 2 patients, as well as the additional case reports mentioned above, suggest that a third type of learning disability, associated with bilateral prefrontal lesions, may lead to major deficits in the maturation of judgement, insight, foresight, abstract reasoning, perspective taking, empathy and moral development.

Anatomical and physiological observations show that the prefrontal cortex provides a template for the convergence of limbic inputs with extensively processed associative 
information (Mesulam, 1986). This part of the brain is likely to provide one of the most important components of a neural network underlying the integration of thought with emotion (Mesulam, 1985, 1988). The behavioural deficits displayed by our 2 patients are in keeping with the disruption of such a network.

The determinants of functional recovery after brain damage are not fully understood. In a large sample of patients who suffered profound damage to the left hemisphere before the age of 5 yrs most language functions appeared to have developed normally when the subjects were subsequently tested (Lenneberg, 1967). Only subtle deficits emerged when such patients were challenged with more difficult language tasks (Dennis and Whitaker, 1976). Equivalent lesions acquired during adulthood would be expected to yield much more severe and permanent aphasias. A different temporal relationship appears to characterize the impact of frontal lobe damage. Our 2 patients suggest that early bilateral frontal lesions may leave permanent uncompensated deficits that persist into adulthood. It even appears as if bifrontal lesions yield behaviours that are more chaotic and aberrant when the damage is acquired early in life rather than during adulthood.

Our patients' lack of premeditation, the remarkable clumsiness in committing crime, and the lack of predisposing factors in the social background distinguish them from others who are designated as sociopaths. The extent to which frontal lobe lesions underlie deviant and criminal behaviour in the general population is difficult to surmise. Several investigations of incarcerated juvenile delinquents have reported a profile of neuropsychological deficit that resembles the pattern displayed by our 2 patients (Moffitt and Silva, 1988). A recent study of juveniles condemned to death revealed that the majority had a history of head trauma, EEG abnormality and abnormal performance in tests of reasoning and mental flexibility (Lewis et al., 1988). Conceivably, a subset of these individuals could have underlying bifrontal dysfunction acquired early in life or even during the stage of prenatal development. In some of these cases, the dysfunction could be at a neurochemical or physiological level not detectable by conventional neurodiagnostic methods.

The 2 patients described in our report show that bifrontal dysfunction acquired early in life may lead to a specific subtype of learning disability by selectively interfering with the acquisition (or development) of many complex faculties such as insight, foresight, social judgement, empathy and abstract reasoning. Diagnosis may be particularly challenging. The predominantly behavioural presentation in the absence of focal elementary neurological signs may lead to the erroneous impression that the underlying factors are primarily psychiatric or environmental.

\section{ACKNOWLEDGEMENT}

We are grateful to Drs Guerry Peavey and Paul Spiers for neuropsychological testing, Joseph Joyce for social investigation of Case 1, and Sheila Golden for technical assistance in the preparation of the manuscript.

\section{REFERENCES}

ACKERLY S (1935) Instinctive, emotional and mental changes following prefrontal lobe extirpation. American Journal of Psychiatry, 92, 717-729. 
ACKERLY SS (1964) A case of paranatal bilateral frontal lobe defect observed for thirty years. In: The Frontal Granular Cortex and Behavior: a Symposium. Edited by J. M. Warren and K. Akert. New York and London: McGraw-Hill, pp. 192-218.

ACKeRLY SS, BENTON AL (1948) Report of a case of bilateral frontal lobe defect. Research Publications: Association for Research in Nervous and Mental Diseases, 27, 479-504.

BENTON AL (1968) Differential behavioral effects in frontal lobe disease. Neuropsychologia, 6, 53-60.

Benton AL, Hamsher de S (1976) Multilingual Aphasia Exam. Iowa City: University of lowa.

BERG EA (1948) A simple objective technique for measuring flexibility in thinking. Journal of General Psychology, 39, 15-22.

BRICKNER RM (1936) The Intellectual Functions of the Frontal Lobes: a Study Based upon Observation of a Man after Partial Bilateral Frontal Lobectomy. New York: Macmillan

DENNIS M, WHITAKER HA (1976) Language acquisition following hemidecortication: linguistic superiority of the left over the right hemisphere. Brain and Language, 3, 404-433.

ESLINGER PJ, DAMASIO AR (1985) Severe disturbance of higher cognition after bilateral frontal lobe ablation: patient EVR. Neurology, Cleveland, 35, 1731-1741.

Eslinger PJ, Damasio AR, Damasio H, GRatTAN L (1989) Developmental consequences of early frontallobe damage. Journal of Clinical and Experimental Neuropsychology, 11, 51.

Feldman MJ, Drasgow JD (1959) The Visual-verbal Test. Los Angeles: Western Psychological Series.

Flavell JH (1968) The Development of Role-Taking and Communication Skills in Children. New York and Chichester: John Wiley.

Galaburda AM (1988) The pathogenesis of childhood dyslexia. In: Language, Communication, and the Brain. Edited by F. Plum. New York: Raven Press, pp. 27-37.

Hebs DO (1945) Man's frontal lobes: a critical review. Archives of Neurology and Psychiatry, Chicago, $54,10-24$.

JASTAK JF, JASTAK SR (1965) The Wide Range Achievement Test Manual. Wilmington, Delaware: Guidance Associates.

Kaplan EF, Goodglass H, Weintraub S (1978) The Boston Naming Test. Philadelphia: Lea and Febiger.

KoHLBERG L (1976) Moral stages and moralization: the cognitive-developmental approach. In: Moral Development and Behavior: Theory, Research, and Social Issues. Edited by T. Lichona. New York: Holt, Rinehart and Winston.

Kohlberg L, Gilligan C (1971) The adolescent as a philosopher: the discovery of the self in a postconventional world. Daedalus, 100, 1051-1086.

Kunn D, Brannock J (1977) Development of the isolation of variables scheme in experimental and 'natural experiment' contexts. Developmental Psychology, 13, 9-14.

LENNEBERG EH (1967) Biological Foundations of Language. New York: Wiley.

Lewis Do, Pincus JH, Bard B, Richardson E, Prichep LS, Feldman M, Yeager C (1988) Neuropsychiatric, psychoeducational, and family characteristics of 14 juveniles condemned to death in the United States. American Journal of Psychiatry, 145, 584-589.

Lhermitte F (1986) Human autonomy and the frontal lobes. Part II: Patient behavior in complex and social situations: the 'environmental dependency syndrome'. Annals of Neurology, 19, 335-343.

Lhermitte F, Pillon B, Serdaru M (1986) Human autonomy and the frontal lobes. Part I: Imitation and utilization behavior: a neuropsychological study of 75 patients. Annals of Neurology, 19, 326-334.

LURIA AR (1973) The Working Brain: An Introduction to Neuropsychology. Translated by B. Haigh. New York: Basic Books.

Mesulam M-M (1985) Patterns in behavioral neuroanatomy: association areas, the limbic system, and hemispheric specialization. In: Principles of Behavioral Neurology. Edited by M.-M. Mesulam. Philadelphia: F. A. Davis, pp. 1-70.

Mesulam M-M (1986) Frontal cortex and behavior. Annals of Neurology, 19, 320-325.

Mesulam M-M (1988) Neural substrates of behavior: the effects of brain lesions upon mental state. In: Harvard Guide to Psychiatry. Edited by A. Nicoli. Cambridge, MA: Harvard University Press, pp. $90-128$.

MiLNER B (1971) Interhemispheric differences in the localization of psychological processes in man. British Medical Bulletin, 27, 272-277.

MiLner B (1982) Some cognitive effects of frontal-lobe lesions in man. Philosophical Transactions of the Royal Society of London, B, 298, 211-226. 
Moffitt TE, Silva PA (1988) Neuropsychological deficit and self-reported delinquency in an unselected birth cohort. Journal of the American Academy of Child and Adolescent Psychiatry, 27, 233-240.

Piaget J (1968) Six Psychological Studies. Translated by A. Fenzer. New York: Random House.

REITAN RM (1958) Validity of the Trail Making Test as an indication of organic brain damage. Perceptual and Motor Skills, 8, 271-276.

RusSELl WR (1959) Brain·Memory Learning. Oxford: Clarendon Press, pp. 107-119.

SELMAN RL (1971) The relation of role taking to the development of moral judgement in children. Child Development, 42, 79-91.

SNAREY JR (1985) Cross-cultural universality of social-moral development: a critical review of Kohlbergian research. Psychological Bulletin, 97, 202-232.

STROOP JR (1935) Studies of interference in serial verbal reactions. Journal of Experimental Psychology, $18,643-662$.

WeCHSLER DA (1981) The Wechsler Adult Intelligence Scale - Revised Manual. New York: Psychological Corporation.

Weintraub S, Mesulam M-M (1983) Developmental learning disabilities of the right hemisphere: emotional, interpersonal, and cognitive components. Archives of Neurology, Chicago, 40, 463-468.

Weintraub S, Mesulam M-M (1985) Mental state assessment of young and elderly adults in behavioral neurology. In: Principles of Behavioral Neurology. Edited by M.-M. Mesulam. Philadelphia: F. A. Davis, pp. 71-123.

(Received March 15, 1989. Revised August 1, 1989. Accepted October 18, 1989) 